\title{
Location of pupillomotor and accommodation fibres in the oculomotor nerve: Experimental observations on paralytic mydriasis ${ }^{1}$
}

\author{
FREDERICK W. L. KERR AND O. WEEMS HOLLOWELL
}

From the Section of Neurologic Surgery, Mayo Clinic and Mayo Foundation, Rochester, Minnesota, U.S.A.

Hutchinson (1867-68) in his 'Lectures on compression of the brain' was the first to indicate that with an acutely expanding intracranial mass, the ipsilateral pupil frequently dilated and became unresponsive to light. This he attributed to compression of the third nerve. Von Bergmann (1880) and subsequently Macewen (1887) came to similar conclusions regarding the significance of paralytic mydriasis in determining on which side such lesions were to be found. These authors and most subsequent writers on the subject have favoured compression of the third nerve as the most likely mechanism.

A number of reports over the years, however, have suggested another basis for this sign. Cushing (1908) expressed the view that compression of the cerebral hemisphere was responsible and that brief narrowing of the pupil preceded progressive mydriasis. Adrogúe and Balado (1925) said that compression of some structure other than the third nerve should be considered, at least in some instances, since in their experimental and clinical studies the nerve occasionally showed no evidence of trauma. Schörcher (1937), on the basis of experimental and clinical data, stated categorically that compression of the oculomotor nerve was not a factor in the early phases of paralytic mydriasis and that irritation of sympathetic pathways in the brain-stem should be regarded as the predominant mechanism. Reid and Cone (1939) concluded that pressure on the third nerve was the cause of the dilated pupil and pointed out that because of the close association of pupilloconstrictor centres in the midbrain it was highly improbable that unilateral mydriasis would occur from pressure there. Nelson (1942) and Penfield and McEachern (1949), however, attributed paralytic mydriasis to compression of the brain-stem.

Current opinion favours trauma to the third nerve, and among more recent studies sponsoring this view-

'This investigation was supported in part by research grant B-3296 from the National Institutes of Public Health Service, and the paper was read at the meeting of the Society of Neurological Surgeons, Rochester, Minnesota, 7-9 May 1964. point are those of Welte (1943), Sunderland and Hughes (1946), Sunderland and Bradley (1953), Lazorthes, Pigassou, and Gaubert (1955), Sunderland (1958), Weintraub (1960), Jennett and Stern (1960), and Keefe, Rucker, and Kernohan (1960).

In a recent study of pupillomotor pathways in the spinal cord in the cat (Kerr and Brown, 1964), the ease with which paralytic mydriasis could be produced, occasionally lasting for a number of hours, in response to a single episode of trauma to the cervical or upper thoracic cord, again raised the possibility that compression of the brain-stem and irritation of the sympathetic pupillomotor pathway might play a significant role in this response. The fact that lateral compression of the cord led to ipsilateral pupillodilatation appeared to detract from the point made by Reid and Cone (1939) that proximity of pupillomotor centres ruled out unilateral pupillary changes in response to pressure, since in the thoracic spinal cord of the cat the right and left ciliospinal centres are separated by a distance of less than $2 \mathrm{~mm}$.

For these reasons we decided to re-evaluate the mechanisms of pupillary-dilatation secondary to increased pressure and to test the theories by applying pressure under direct vision to various supratentorial structures.

As the study progressed, it became necessary also to determine the course of the pupillomotor fibres in the third nerve, since some conflict of opinion exists in the literature on this point. The most generally accepted view is that of Sunderland and Hughes (1946) who stated that small fibres are most numerous on the superior arc of the third nerve in its proximal course near the brain-stem and concluded that these were the fibres that passed to the inferior division and thence to the ciliary ganglion. Lyle (1954), however, noted that the pupillomotor fibres probably proceed down the central part of the nerve, a view first proposed by St. Bernheimer (1897) and later by Fuchs (1907). Lazorthes et al. (1955) stated that these fibres emerge from the brain-stem on the medial aspect of the nerve from whence they pass laterally 
to reach the inferior surface. The precise location of these fibres is of some practical importance in trying to determine the mechanism of paralytic mydriasis, particularly in view of the well-known observation (Wilson, 1949; Huber, 1961) that a relatively pronounced degree of pupillary dilatation may result from pressure, without any clinically detectable impairment of extraocular motility but Jennett and Stern (1960) cast some doubt on this observation. The dissociation of intraocular and extraocular motility has been variously accounted for. Some investigators have considered the pupillomotor fibres more vulnerable to pressure, a suggestion which is at variance with the greater resistance of small fibres to pressure block, while others think that the pupillomotor fibres are located in a more vulnerable position.

\section{MATERIAL AND METHODS}

The animals used for the compression and stimulation studies included 10 dogs, one Macacus rhesus, and one baboon (Papio papio); in addition, some of the studies on dogs in which direct pressure was applied to the brainstem and to the third nerve were repeated on three cats. For all experimental procedures deep pentobarbital sodium anesthesia was used; supra-collicular decerebration with removal of the brain rostral to this plane was carried out in those experiments in which stimulation of the third nerves was to be done.

COMPRESSION STUDiEs Pressure was applied to the convexity and to the medial and the inferior aspects of the hemisphere. A Chatillon gauge was used in these and other studies of this type to estimate in grams per square centimetre the actual pressure applied. Pressure was applied to the lateral aspect of the brain-stem at the level of the tentorial notch by means of a foam rubber cushion cut to the approximate size and shape of the medial aspect of the temporal lobe. In other studies, pressure was applied vertically on the quadrigeminal plate, also by means of a small foam rubber cushion, or transversely to compress the tegmentum at the level of the third nerve nucleus without lateral displacement. Finally, pressure, measured by a Chatillon gauge, was applied directly to the third nerve in a similar manner. These observations on the effects of pressure can be regarded only as relatively gross approximations.

STIMULATION STUDIES The usual stimulus employed was $6 \mathrm{v} ., 60 / \mathrm{sec}$., $1 \mathrm{msec}$., square wave pulses delivered by a Grass stimulator via standard insulated monopolar steel electrodes, the indifferent electrode being placed in the paravertebral musculature. When the preganglionic pathway in the third nerve was being traced, steel microelectrodes were used to restrict the area of stimulation to a minimum, and stimuli which were just suprathreshold to maximal were used. Thus discrete identification of the fibres was possible. Since marked miosis is present in decerebrate animals in good condition, it was necessary in most instances to produce pupillary dilatation as preliminary step to stimulation of the pupillomotod fibres in the third nerve. This was usually obtained bf means of mild compression of the nerve as it left the brain-stem and was cross-checked in experiments i which the nerve had not been touched; in others in which the nerve was completely transected at the brain-stenw? the nerve was stimulated distal to the section, and in stion other experiments mydriasis was produced by sustaine stimulation of the cervical sympathetic chain, and durin the resultant mydriasis various aspects of the third nerve were stimulated. In addition to stimulation of the thire nerve, multiple points of the cortex, again including the medial and inferior aspects of the hemisphere, were stimulated to determine the areas from which pupillo motor responses could be obtained before carrying out compression experiments.

The effect of sectioning various quadrants of the third nerve was studied also. The four quadrants of the nerve were marked by introducing fine rigid steel wires throug the nerve at right angles to each other (a procedure which did not influence the diameter of the pupil or the res sponse); following this, individual nerve quadrants were: relatively accurately sectioned with fine iris scissors. In other instances, the nerve was sectioned progressive from lateral to medial or vice versa.

Pupillary responses were photographed by means of Grass camera triggered by a relay at 2 or 5 frames $\Phi$ er second; a cystoscope lamp bulb on the animal's foreheafp signalled the beginning and end of stimulation. Ofhe details of technique are as described elsewhere (Kerr and Brown, 1964).

HISTOLOGICAL STUDY Ten oculomotor nerves from two from macaques, and four from dogs were studied. The lateral and superior aspects of all the nerves marked with a narrow stripe of red and of green plast paint, respectively; this was allowed to dry before placing the specimen in $10 \%$ formalin. These identifica tion marks were applied with the nerve and brain in sit since, on sectioning the nerve just distal to the poirif where it enters the dura, considerable external rotation tended to occur. Three segments were cut from each nerv』 one at the emergence from the brain-stem, one at the midpoint in the subarachnoid space, and one at the leve where the nerve pierces the dura.

The plastic marking resisted subsequent processing the nerve until sections were attached to the slides; de paraffinizing frequently removed the markers. Therefore: their position was identified on the slide with a diamond point before deparaffinizing.

Sections were cut at 8 microns and stained by the Bodian technique.

\section{RESULTS}

COMPRESSION STUDIES Pressure applied to any all points of the cerebral hemispheres (including the basal aspects) for 30 to 60 seconds or more had nf effect on the size of the pupils provided the direction in which the pressure was applied did not compress 
or distort the third nerve. The degree of pressure applied was well in excess of systolic blood pressure and often resulted in a depression of the cortex which persisted for a considerable time after pressure was discontinued. When pressure was applied to the lateral aspect of the brain-stem (dog), no change in pupillary size occurred until the third nerve was stretched or compressed. Prompt ipsilateral dilatation then occurred. With further rather intense pressure the contralateral pupil would begin to dilate also, owing to stretching of the opposite third nerve. On release of the compression this pupil returned to normal size before the ipsilateral pupil. Compression of the midbrain by a downward vertical force, applied to the collicular plate in the dog, resulted either in no change in pupillary size until the third nerves became compressed, at which time pupillary dilatation began, or in an early clear-cut pupillary constriction which was bilateral and symmetrical and lasted for some time beyond the cessation of compression, provided, of course, that the third nerve was not compressed also. Figure 1a shows miosis produced in this manner in the dog.

Compression of the third nerve resulted in pupillary dilatation with relatively mild degrees of pressure; this was particularly true for pressures exerted medially and downward at the point where the nerve passes through the dural foramen. Although we measured pressures as noted previously, it is our belief that the actual figures would be quite mis-
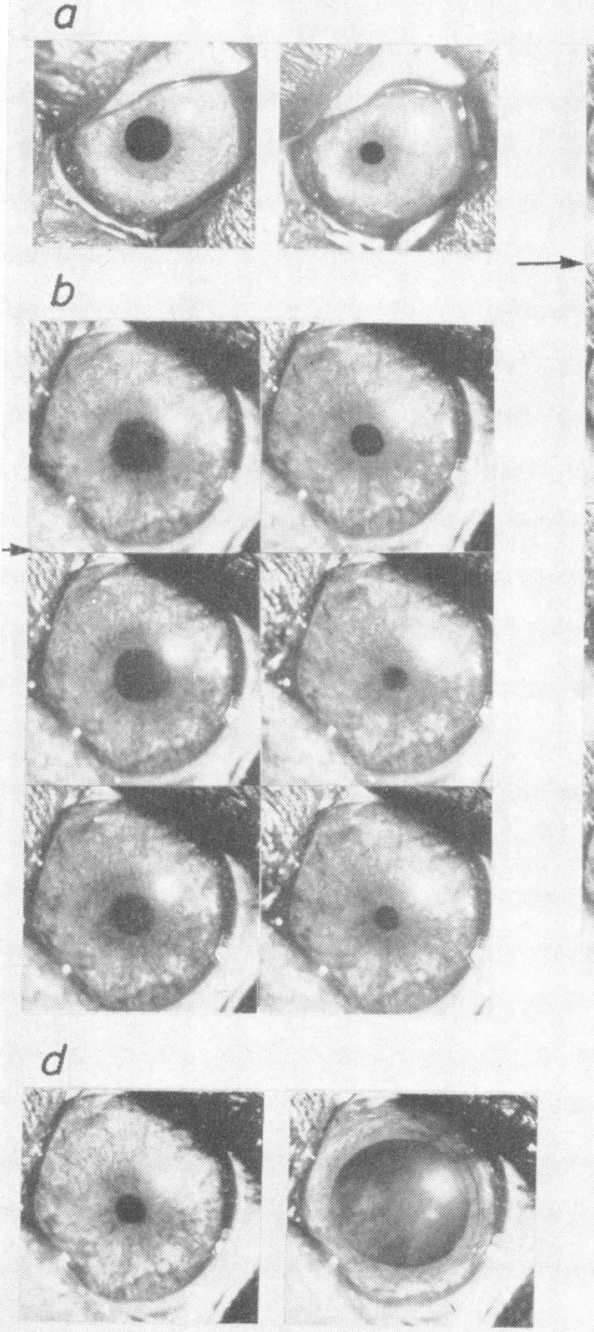

\section{C}

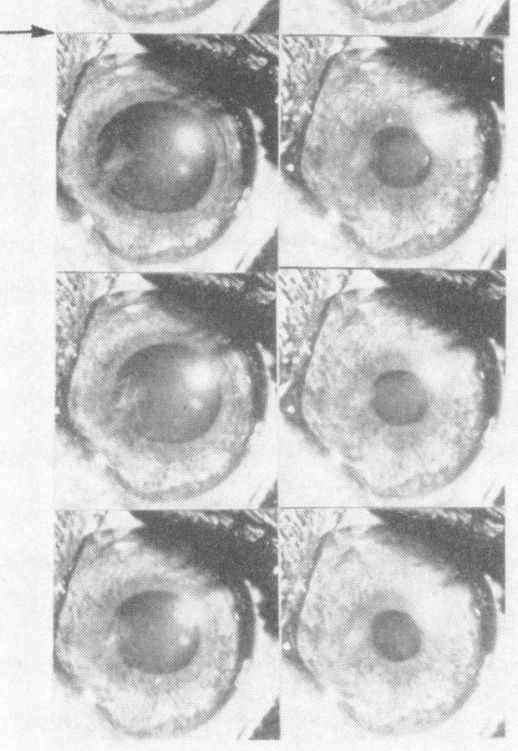

FIG. 1. The left pupil only is illustrated in this figure. (a) Miosis produced by compression of the collicular plate. Pupil before (left) and during (right) compression.

1b. Response of left pupil to stimulation of medial aspect of the third nerve $2 \mathrm{~mm}$. from brain-stem. First frame, resting state; at second frame onset of stimulus of 2 v., 60/sec., 1 msec. which resulted in progressive marked pupillary constriction. Five frames per second; every third frame is shown. Sequence of frames is from above down in each column. Stimulation of latera. surface of the nerve at the same parameters produced no pupillary response.

1c. Third nerve compressed lightly at brain-stem to produce mydriasis and procedure described in Fig. 16 was repeated; stimulus was applied to the medial aspect of the nerve where it pierces the dura. First frame resting state; onset of stimulus at second frame. Stimulus parameters and sequence of frames is the same as for Fig. $I b$.

1d. Pupil before (left) and after (right) section of medial superficial fibres. The part of nerve sectioned corresponded approximately to the intact area in Fig. 2b. All in the dog. 
leading, since minimal changes in the direction of applied pressure resulted in significant changes in size of the pupil, but marked changes in pressure in a given direction were often without effect.

The conclusion that may be drawn, however, on the basis of repeating the compression experiments many times, both in the same and other animals, is that the third nerve is by far the most sensitive structure to pressure in so far as the production of mydriasis is concerned; pressures of equal or greater intensity applied to the cerebral cortex, the lateral or dorsal aspect of the brain-stem at the level of the tentorial notch, being either without effect or, as in the case of the quadrigeminal plate, result in miosis.

STIMULATION OF THE THIRD NERVE Using graded electrical stimuli as described under Methods and with both third nerves exposed from the brain-stem to the dural penetration, the nerve was stimulated at successive points around its circumference; this was done at the point of emergence of the nerve from the midbrain, at the point where the dura was penetrated, and midway between these two points. Some variation in the response occurred from animal to animal, and the description which follows corresponds to the most typical experiments. Stimulation of the superior surface of the nerve at its emergence from the midbrain resulted in maximal pupillary constriction, particularly on the medial half of the superior surface. Stimulation of the lateral and inferior quadrants of the nerve at this level had no effect on the pupil, while stimulation of the medial surface resulted in progressively less response as the stimulus was applied farther from the dorsomedial aspect.

At the midpoint of its subarachnoid course, the maximal response was obtained from the medial aspect of the nerve, either exactly on the horizontal meridian (Fig. 1b) or slightly above or below this point. Again stimulation on the dorsal, lateral, or ventral aspects of the nerve produced either minimal or no pupillary changes. From the area of maximal response, the pupillary constriction decreased progressively as stimulus was applied more dorsally or ventrally.

When the nerve was stimulated at the dural foramen, the maximal response was obtained again from stimulation of the medial aspect (Fig. 1c), that is, from stimulation of the fibres occupying a position similar to or identical with those that gave the maximal response in the mid portion of the nerve. However, at the dural foramen the fibres appeared to be more spread out and a fairly pronounced response was usually obtained from the ventrolateral aspect of the nerve also.

STIMULATION OF THE CORTEX Cortical stimulation was done to identify areas from which a pupillary response to pressure might be expected and not as $\underset{\mathbb{D}}{Z}$ a study of electrically evoked pupillary responses $\frac{\subsetneq}{\circ}$ per se.

The areas of the cerebral cortex which were $\stackrel{\overline{0}}{\stackrel{c}{0}}$ stimulated in the dog included the whole of the con- 0 vexity, the medial aspect, including the cingulate gyrus and the ventral aspect of the temporal lobe, $\stackrel{?}{?}$ and the hippocampal gyrus. In general, pupillary responses to a stimulus of $6 \mathrm{v} ., 60 / \mathrm{sec}$., $1 \mathrm{msec}$. were. negligible or minimal amounting to less than $1 \mathrm{~mm}$. $\overrightarrow{\vec{s}}$ of change in diameter from all points tested on the convexity with the exception of the most lateral $\frac{}{0}$ aspect of the cruciate gyrus at which point a sym- $\bar{c}$ metrical dilatation of approximately $2 \mathrm{~mm}$. occurred. $\vec{\nabla}$

The most pronounced dilatation resulted from $\triangle$ stimulation of the ventral surface of the hippocampalis gyrus at about its midpoint; in these instances $\overrightarrow{0}$ mydriasis from a diameter of approximately $1 \mathrm{~mm}$. up to approximately 5 to $6 \mathrm{~mm}$. occurred in the $\vec{\omega}$ contralateral pupil while the ipsilateral pupil showed a less marked response. This pupillary response was obtained repeatedly with the same characteris-i tics. The contralateral cervical sympathetic chain. below the superior ganglion was then sectioned, when the same cortical area was stimulated, cleaf $\omega$ cut but less marked pupillary dilatation occurredo on the side of the sympathectomy, the response the side of the intact sympathetic chain being up changed.

TRANSECTIONS OF THE THIRD NERVE With the dafa from stimulation, the third nerve was progressivete

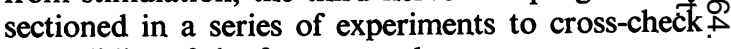
the validity of the former results.

The sections of the nerve were carried out at the midpoint of its course in the subarachnoid space or at the point where the nerve passed into the dura and stimulation was applied proximal to the severed $\frac{0}{8}$ portion of the nerve (Fig. 2). The lateral half of the $\stackrel{2}{\Rightarrow}$ nerve could be transected at these levels without any을 effect on pupillary response to stimulation of the nerve proximal to the lesion (Fig. 2a). Further sectioning of the nerve to include the central or axial portion likewise produced no change. When all that remained of the nerve was a thin, almost translucento band of the most medial fibres, the pupillary response $\frac{3}{3}$ remained unchanged (Fig. 2b). Progressive section-ing of this medial husk of the nerve then resultedo in gradual deterioration of the pupillary response, which disappeared as the last fibres were transected. In the experiment on the baboon on which Fig. 2D is based, the pupil was initially mydriatic.

Section of the third nerve in the reverse direction, $N$ that is, from medial to lateral, resulted in initial dilatation of the pupil, but full dilatation did not 


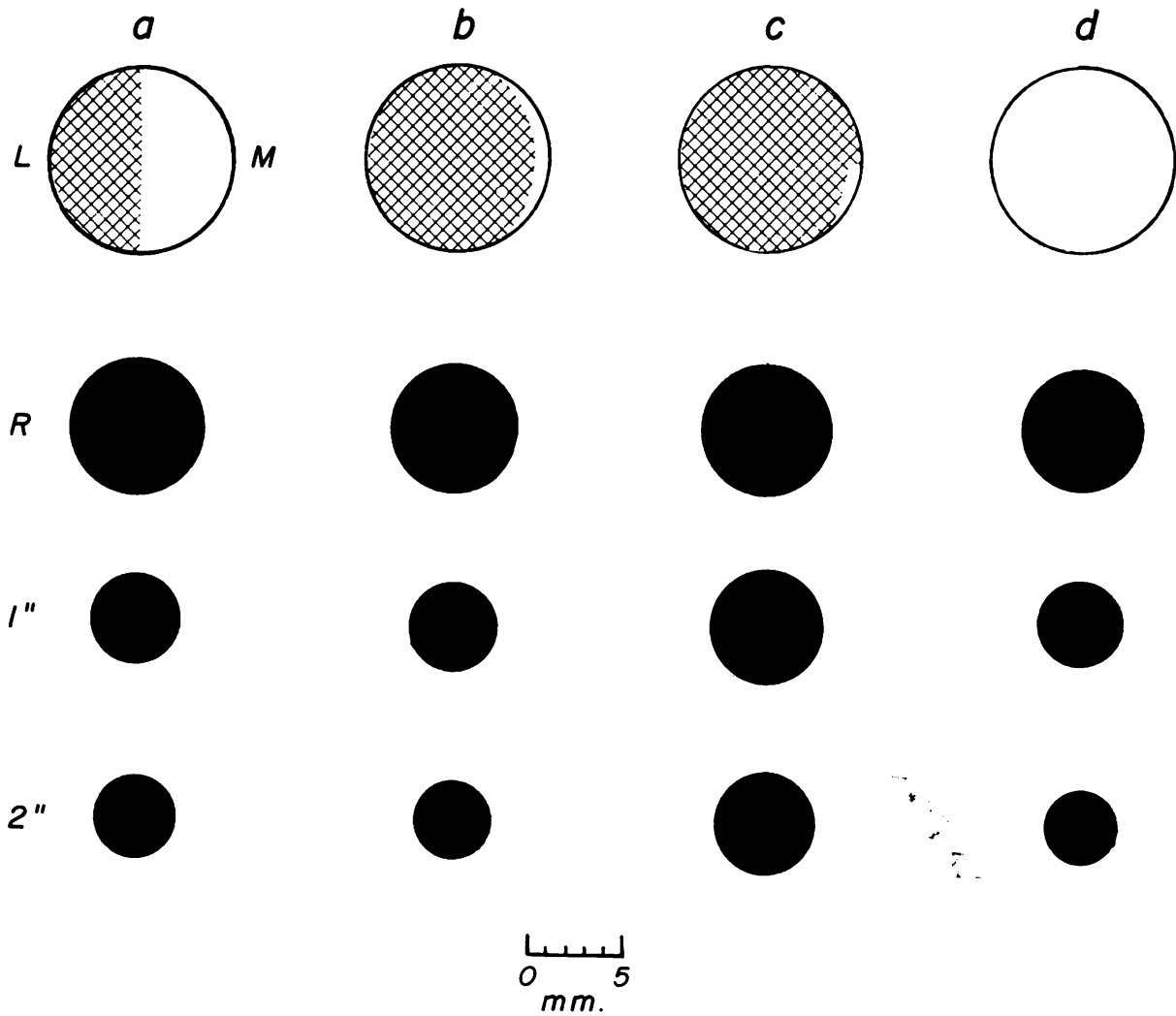

FIG. 2. Effect of progressive sectioning of the third nerve (baboon) at dural penetration point on electrically evoked pupillary response. Stimulus of $10 \mathrm{v}$., 60/sec., $5 \mathrm{msec}$. was applied to medial aspect of nerve $2 \mathrm{~mm}$. from brain-stem.

2a. Lateral $(L)$ half sectioned. 2 b. Lateral four-fifths sectioned. 2c. Small ventromedial bundle remaining. $2 \mathrm{~d}$. Response from intact nerve for comparison.

Upper row. Pupil at rest. Middle and lower rows. Response at 1 and 2 seconds, respectively, from onset of stimulation. Scale for pupil diameter in millimetres. Discussion in text.

occur in some instances until the whole of the nerve had been transected, and a mild response could be obtained to stimulation proximal to the section when the medial half of the nerve had been transected. This indicates that, despite negative results of stimulation, some pupillomotor fibres run in the lateral half of the nerve and this small number of pupillomotor fibres is sufficient to maintain a degree of pupillary tone. However, in some instances section of the most medially placed fibres at the midpoint in the subarachnoid course caused immediate and pronounced paralytic mydriasis (Fig. 1d). No changes in pupillary contour (discoria) occurred as a result of these partial transections, the dilatation being regular and progressive. Section of the nerve in quadrants also confirmed these observations; in some instances the cut surface of the distal stump of the nerve was stimulated. No pupillary response was obtained from stimulation of the central part of the nerve, whereas the maximal response was elicited from the medial and superficial aspects.

OBSERVATIONS ON ACCOMMODATION During the course of these observations on pupillary constriction in response to localized stimulation of the third nerve, changes in accommodation were looked for and found. Simple inspection revealed a marked forward displacement of the iris in response to stimulation of the nerve at specific points; this displacement is due to the increased curvature of the anterior surface of the lens which occurs on accommodation (Adler, 1959). That accommodation occurred was also clearly demonstrated by retinoscopy.

In every instance accommodation was associated with pupillary constriction, whereas no accommoda- 

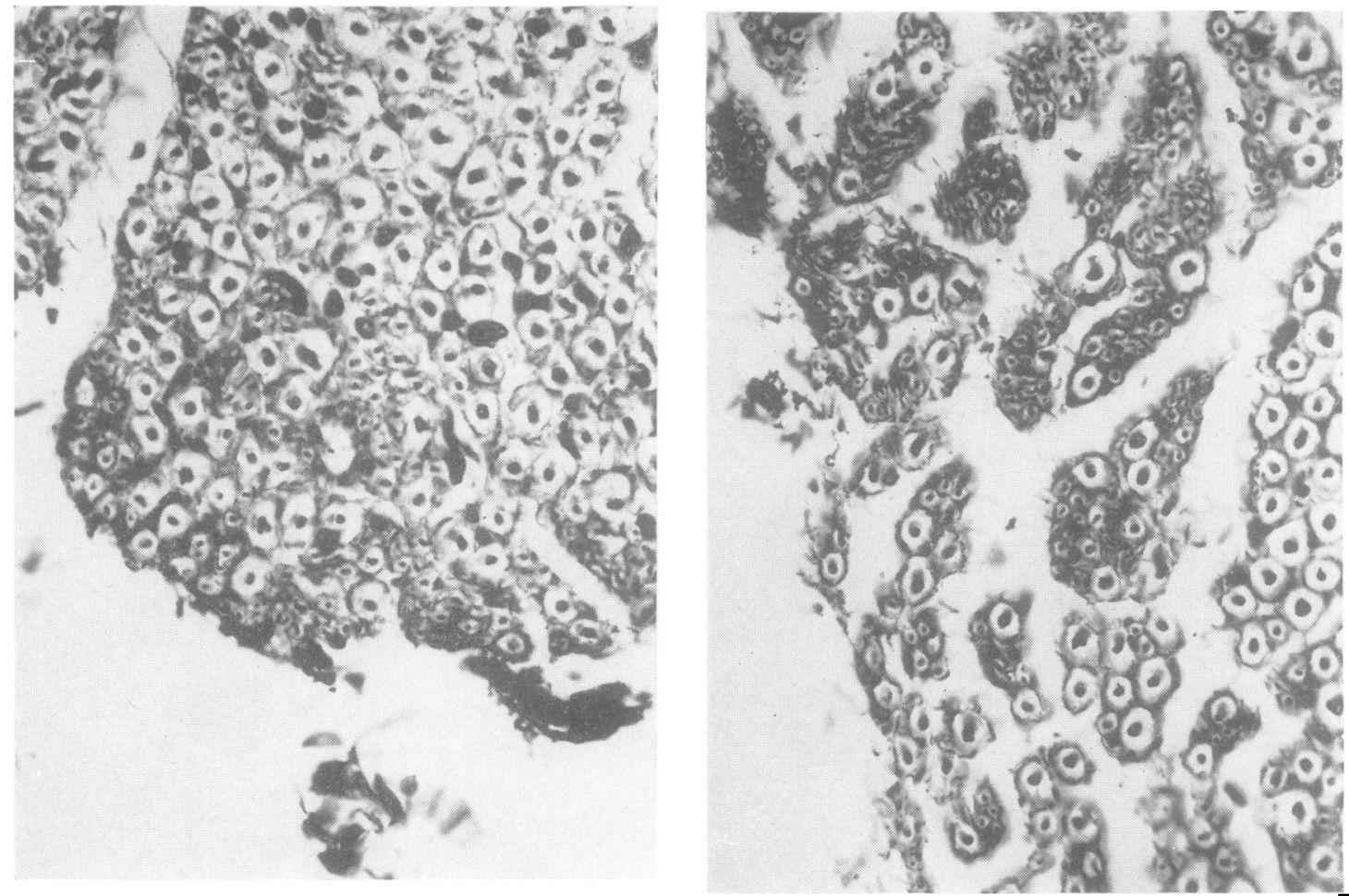

FIG. 3a

FIG. $3 b$

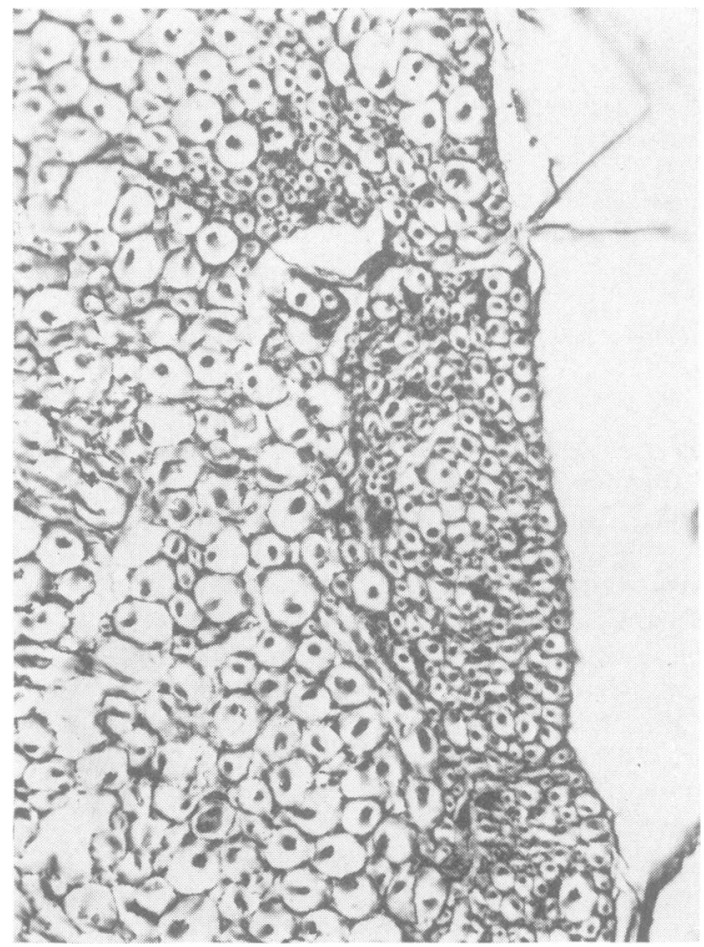

FIG. 3c

FIG. 3d

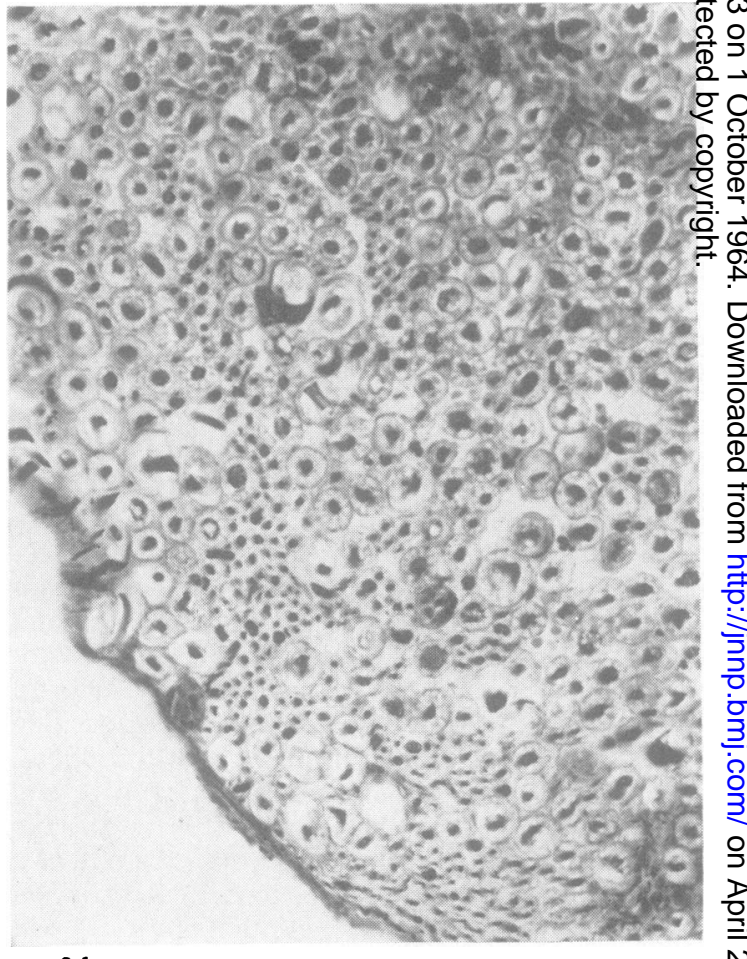

FIG. 3. Pupillomotor fibres in the third nerve in man monkey, and dog 3a. At brain-stem in man these fibres are contained 0 in a few fine strands in the superomedial angle $(\times 500) .3 \mathrm{~b}$. At the midpoint in the subarachnoid space $(\times 500)$. 3c. At the $\mathrm{N}$ brain-stem in the monkey (M. rhesus) they form a conspicuous layer beneath the epineurium $(\times 500) .3 \mathrm{~d}$. In the dog they $\omega$ are also conspicuous and can be seen superficially as well as spreading more deeply between the larger fibres ( $\times$ 425) $\underbrace{0}$ (shown here at the mid-point of the nerve in the subarachnoid space). 
tion occurred when there was no pupillary response to stimulation of the third nerve. It is thus clear that the two responses are mediated by fibres intimately associated in the nerve. Furthermore, when weak pupillary responses were elicited, correspondingly weak accommodation occurred.

HiSTOLOGICAL OBSERVATIONS As noted, sections of the third nerve at the brain-stem, at the point where the nerve pierces the dura, and midway between these two levels were studied.

Fibres fell into two main groups. One of these comprised the large fibres ranging between 10 and $16 \mu$. The other was represented by small fibres of a diameter between about 5 and $1.0 \mu$, which were rather distinctive in the dog and monkey (Fig. 3), since the myelin sheath tended to stain pink to purple and clusters of such fibres were readily identified. They were located readily in both species on the dorsomedial aspect of the nerve at the level of exit from the brain-stem; subsequently, at the middle and more distal parts of the nerve they were found along the most medial aspect of the nerve. These fibres were arranged in small bundles, many of them being placed superficially immediately beneath the epineurium; some of the bundles retained this position while others extended inward for variable but usually small distances between the larger fibres, from which they were quite distinct.

The superficial lateral and ventral aspects of the nerve were devoid of these clusters of small fibres, although isolated groups of small fibres were not uncommon throughout the deeper layers of the nerve. In man the small fibres at or near the surface of the nerve are difficult to demonstrate for reasons which are not clear. Possibly immediate fixation is necessary for good results. We were able to demonstrate them satisfactorily in only two of the 10 human nerves studied. Even in these two they were far less obvious than in the dog and monkey, and it should be noted that in the sections in Fig. 4 an interrogation mark indicates that the fibres seen at the level

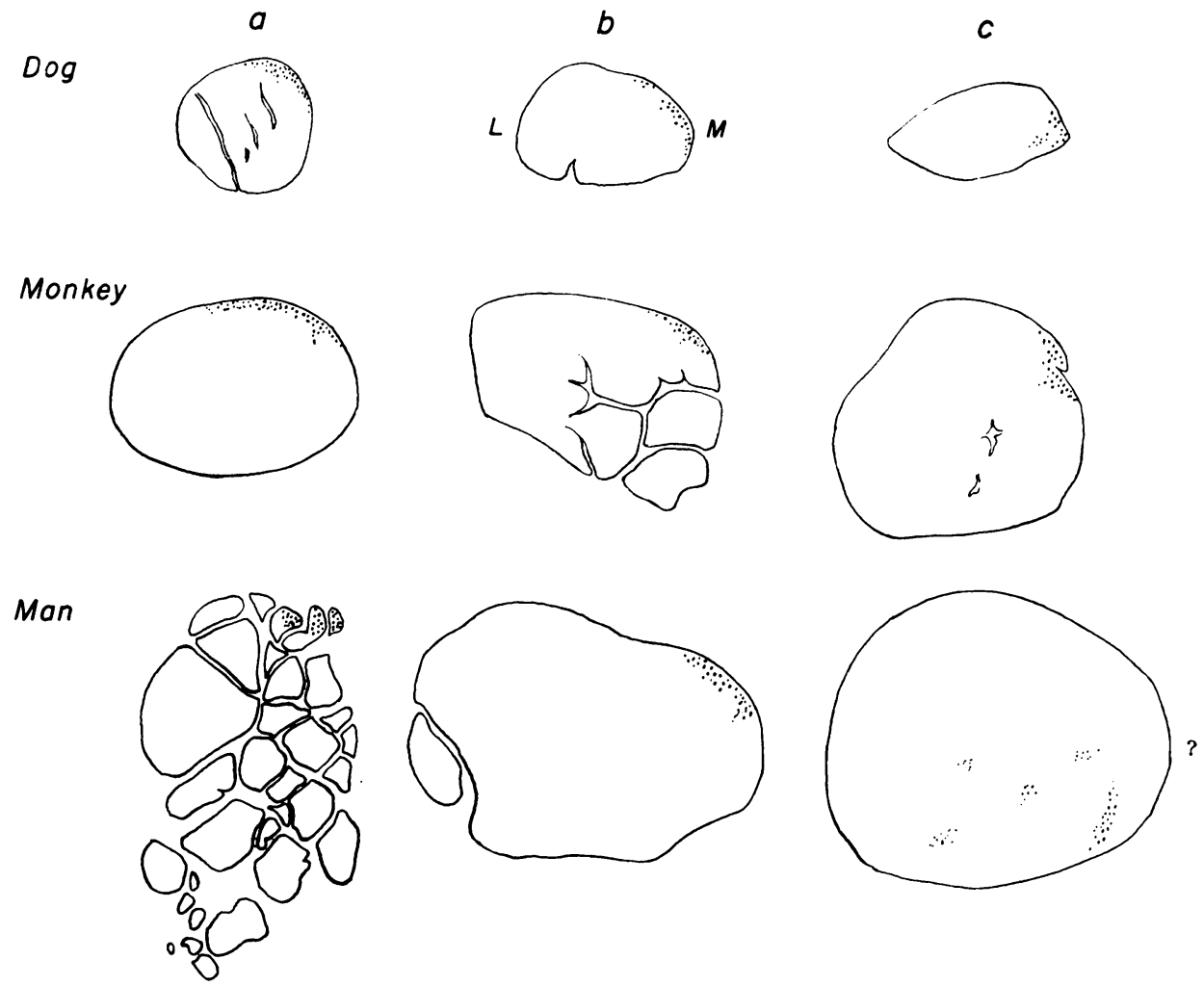

FIG. 4. Location of pupillomotor and accommodation fibres in the third nerve of dog, monkey, and man. 4a. ( first column). At emergence from brain-stem. 4b. Midpoint in subarachnoid space. 4c. At point where nerve pierces dura. All sections are arranged in identical manner, the superior surface being upward; L corresponds to lateral and $M$ to medial aspect, for all diagrams. 
of penetration of the dura, in man, although small, did not show the characteristic clustered arrangement of the fibres we have considered to be pupillomotor in the dog and monkey. Therefore, the location of pupillomotor fibres at the dural foramen in man has not been unequivocally demonstrated, but on a comparative anatomical basis and from the more proximal location of these fibres in the nerve and their ultimate destination to the inferior division, it may be concluded that they lie medially or ventromedially.

\section{DISCUSSION}

From the experiments carried out, many of them gross but nevertheless mimicking a gross phenomenon such as an acute localized rise in intracranial pressure, it appears that compression of supratentorial structures other than the third nerve does not produce mydriasis; when mydriasis does occur it is almost certainly due to transmitted pressure or distortion of the nerve.

Some authors (Cushing, 1908; Dott, 1939; Fischer-Brügge, 1951, among others) have stated that a brief period of ipsilateral miosis may precede the onset of paralytic mydriasis. Cushing considered both phenomena due to compression of the hemisphere while Fischer-Brügge attributed them to pressure on the third nerve. Although a transient slight constriction of the pupil was noted in response to direct compression of the third nerve on one occasion in our experiments, this was so unusual that little significance can be attached to it. Certainly, from the clinical point of view a response as brief as this (lasting for a few seconds) would almost certainly pass unperceived. Compression of the collicular plate resulted in marked miosis in the cat and occasionally in the dog; it may be assumed that this is due to stimulation of the underlying parasympathetic centre. Unilateral miosis was not observed, however. Even rather intense pressure leading to persistent deformation of the tegmentum did not result in mydriasis, and it is interesting to note in this regard that compression with corresponding ischaemic anoxia either of the parasympathetic pupilloconstrictor outflow as described herein or of the sympathetic pupillo-dilator outflow (Budge's ciliospinal centre, Kerr and Brown, 1964) gives rise to signs of irritation or activation and not to paralysis. It is probable that if compression were sustained paralysis would ensue but we did not prolong compression much beyond 30 to 60 seconds in these studies. These observations may be of some significance in explaining the miosis that precedes paralytic mydriasis. Since compression of the third nerve results in only fleeting miosis, and rarely at that, tegmental compression would appear to be a more likely mechanism. Failure to observe strictly ipsto lateral miosis in our experiments tends to weakef this hypothesis, however.

With regard to pupillary dilatation in response t⿳⺈ localized pressure changes, the evidence appears to be reasonably clear-cut. A cortical origin for pressurs mydriasis can be ruled out since pupillary changes were not produced by pressure at any point on the convexity, the medial or the ventral surface of the brain. When pupillary changes of any significance were produced by electrical stimulation of the cortex? the response was either bilateral and symmetrical of as in the case of the hippocampal gyrus, the contra lateral pupil became larger than the ipsilateral on Thus an irritative cortical lesion would not produce्ष ipsilateral dilatation.

The evidence from this study of the effect of pres $\overrightarrow{0}$ sure applied under direct vision to supratentoriat structures indicates that mydriasis is produced mos readily by compression of the third nerve. This mydriasis is reversible, but with repeated compres? sion becomes fixed. The direction of applied pressures was more significant than the degree of pressure within certain limits. Thus, compression of the netis against medially placed structures near the pointod exit from the subarachnoid space produced mydriasio with relatively mild pressures, whereas direct verti̊al pressure of the same degree on the nerve at this legeD was much less effective. This correlates with the् observation that marked generalized increasegin intracranial pressure may develop (Browder atd Meyers, 1939) without significant changes in pupilo lary function, whereas less pressure with displacement ${ }^{\mathbb{P}}$ of the intracranial contents frequently results inp paralytic mydriasis.

The determination of the position of the pupillo motor fibres in the third nerve is based on botkp anatomical and functional studies. Since the result 8 of these two methods are in close agreement, it may be stated that, between the brain-stem and the exip of the nerve from the subarachnoid space, these fibres lie along the dorsomedial and medial aspect of the nerve and have a gradually descending course as they run forward. Furthermore, they are located very superficially, most of them being immediately? beneath the epineurium.

One discrepancy in our experiments should be noted, however; thus, while a fairly brisk contraction of the pupil could usually be obtained from the ventrolateral aspect of the nerve near the point of dural penetration, no definite aggregation of fine fibres could be demonstrated histologically at this: point. It is possible that some of the scattered fines: fibres seen throughout the nerve may mediate pupillomotor functions and thus account for the discrepancy 
between stimulation and structural findings in this instance.

The location of the pupillomotor fibres as described here confirms the observations of Sunderland and Hughes (1946) and supports, from the structural point of view, the mechanism of compression of the superior surface of the third nerve by the posterior cerebral artery as described by Fischer-Brügge (1951), Sunderland and Bradley (1953), Keefe et al. (1960), and others. On the other hand, the medial position of these fibres at the level of the posterior clinoid and the dural penetration points also supports the suggestion of various authors (Reid and Cone, 1939; Fischer-Brügge, 1951; Lazorthes et al., 1955) that pressure against medially placed structures at this level is responsible.

ACCOMMODATION There has been up to the present time no information regarding the course of fibres mediating accommodation, and although the observations made during the course of this study cover only a very short part of this pathway, they indicate that, at least in the third nerve, the fibres for accommodation are intimately associated with the pupillomotor fibres.

\section{SUMMARY}

Study of the effect of compression and stimulation of the third nerve of several species of animals and histological study of the nerves yielded the following findings.

The third nerve is the only supratentorial structure which on being compressed gives rise to mydriasis.

Compression of the brain-stem tegmentum at the level of the oculomotor nucleus results in miosis, not mydriasis.
The position of the pupillomotor fibres in the third nerve has been determined by stimulation, partial neurotomies, and histological study, results from these methods being in close agreement.

The fibres mediating accommodation run with the pupillomotor fibres in the third nerve.

The authors wish to express their appreciation to Drs. W. D. Backer and P. L. Archambeau for performing retinoscopic examinations.

\section{REFERENCES}

Adler, F. H. (1959). Physiology of the Eye: Clinical Application, 3rd ed. Mosby, St. Louis.

Adrogué, E., and Balado, M. (1925). Rev. Asoc. méd. argent., 38, 252

Bergmann, E. von (1880). Die Lehre von den Kopfverletzungen. In Billroth and Luecke. Deutsche Chirurgie, pt 30, p. 398. Enke, Stuttgart.

Browder, J., and Meyers, R. (1939). Ann Surg., 110, 357.

Cushing, Harvey (1908). Surgery of the head. In Keen's Surgery, vol. 3 , p. 204. Saunders, Philadelphia.

Dott, N. (1939). In Thomson and Miles' Manual of Surgery. Oxford University Press, London.

Fischer-Brügge, E. (1951). Acta neurochir. (Wien), 2, 36.

Fuchs (1907). Arb. neurol. Inst. Univ. Wien, 16(2), 245.

Huber, A. (1961). Eye Symptoms in Brain Tumours. Mosby, St. Louis.

Hutchinson, J. (1867-1868). Clin. Lect. Rep. Lond. Hosp., 4, 10.

Jennett, W. B., and Stern, W. E. (1960). J. Neurosurg. 17, 598.

Keefe, W. P., Rucker, C. W., and Kernohan, J. W. (1960). Arch. Ophthal., 63, 585.

Kerr, F. W. L., and Brown, J. A. (1964). Arch. Neurol. (Chic.). 10, 262.

Lazorthes, G., Pigassou, R., and Gaubert, J. (1955). Bull. Soc. belg. Ophthal., 109, 16.

Lyle, D. J. (1954). Neuro-ophthalmology, 2nd ed. Thomas, Springfield, Illinois.

Macewen, William (1887). Amer. J. med. Sci., 94, 123.

Nelson, J. (1942). J. Amer. med. Ass., 119, 864.

Penfield, W., and McEachern, D. (1949). In The Oxford Medicine, vol. 6 , pp. 137-216.

Reid, W. L., and Cone, W. V. (1939). J. Amer. med. Ass., 112, 2030.

St. Bernheimer (1897). Albrecht v. Graefes Arch. Ophthal., 44, 526.

Schörcher, F. (1937). Dtsch. Z. Chir., 248, 420.

Sunderland, S. (1958). Brit. J. Surg., 45, 422.

- , and Bradley, K. C. (1953). J. Neurol. Neurosurg. Psychiat. 16, 35.

, and Hughes, E. S. R. (1946). Brain, 69, 301.

Weintraub, C. M. (1960). Brit. J. Surg., 48, 62.

Welte, E. (1943). Zbl. Neurochir., 8, 217.

Wilson, W. C. (1949). Arch. Neurol. Psychiat. (Chic.), 61, 385. 